$120 \mathrm{~mm}$. Hg. On the 16 th the blood pressure was $120 \mathrm{~mm} . \mathrm{Hg}$, dyspncea was again verp well marked, there was severe abdominal pain-mainly on the right side-and no urine was passed. The temperature ran up on the right side-and no urine was passed. The temperature ran up
to $102^{\circ} \mathrm{F}$. and the pulse to 136 . On the 17 th the temperature had to $102^{\circ} \mathbf{F}$. and the pulse to 136 . On the 17 th the temperature had
fallen to $970^{\circ}$, and there was slight twitching of the face. At 2.30 P.M. fallen to $97^{\circ}$, and there was slight twitching of the face. At 2.30 P.M.
the blood pressure had fallen to $60 \mathrm{~mm}$. Hg; at 3.30 P.M. the face the blood pressure had fallen to $60 \mathrm{~mm}$. Hg; at 3.30 P.M. the face mentally alert to the end. There was no vomiting while in the hospital, mentally alert to the end. There was no vornit

and no cedema of the subcutaneous tissues. $R$. H. Turton. The right The necropsy was performed by Mr. J. R. H. Turton. The right
utero-ovarian plexus of veins was filled with dark blood-clot and produced a prominent swelling at the commencement of the right ovarian vein in the upper part of the broad ligament. There was not any extension of the clot into the iliac veins. The right ovarian vein was completely distended with clot and formed a conspicuous object on the posterior wall of the abdomen. The clot, about an inch in length and a quarter of an inch in diameter, projected into the inferior vena cava, lying free in the lumen of the vessel but not filling its cavity. The right ovarian vein opened into the inferior vena cava about one and $a$ half inches below the renal vein which was free from clot. The left ovarian vein contained some granular clot adberent to its wall opposite the brim of the pelvis. There was a small pale clot, apparently detached from this, at the opening of the left vein. The left renal vein in the hilum of the kidney contained a loose granular clot, extending from the bilum to within three-quarters of an inch of the entrance of the left ovarian vein. The three-quarters of an inch of the entrance of the left ovarian vein. The
vein wall was healthy. The kidneys, $8 \mathrm{oz}$. each, showed symmetrical vein wall was healthy. The kidneys, 8 oz. each, showed symmetrical
necrosis of the cortex, which was dull yellow in colour; there was a thin rim of healthy cortex und $r$ r the capsules. The remaining kidney thin rim of healthy cortex und $+r$ the capsules. The remaining kidney substance appeared bealthy, and the capsules stripped off normally.
The arteries were healthy. Cultures from the spleen and the blood clot The arteries were healthy. Cultures from the spleen and the blood clot in the ovarian vein both showed Streptococcus pyogenes, pure in the
blood clot, but with Bacillus coli in the spleen. The uterus was blood clot, but with
normally involuted.

I am indebte 1 to Dr. Trevor for the following account of the microscopical examination :-

On microscopical examination the necrosis affects the cortex irregu larly in both kidneys. For the most part the whole of the cortex from the medulla to the capsule is affected - a narrow zone only immediately under the capsule being free. The width of this zone even is variable and in one or two places, especially in the left kidney, the necrosis extends quite to the surface, which is slightly depressed. On the medullary side the necrosis reaches downwards in patches to the boundary zone, leaving unaffected areas of cortex in between. The latter, however, are not healthy, the tubal epithelium being degenerated, the cells vacuolated and broken up, whilst many of the tubules contain byaline casts. There is a remarkable absence of any hæmorrhagic zone round the necrotic areas. On the medullary side there are scattered patches of congestion only, and even these are few. There are scattered patches of congestion only, and even these are few. There is a well-marked zone of small-celled infiltration at the periphery of the enclosed portions, and collections of leucocytes are scattered
irregularly throughout them. In the necrotic areas the outlines of the trregularly throughout them. In the necrotic areas the outlines of the tubules can be mane out easily, but the epithelium and the glomeruli are interstitial tissue is also necrotic and does not show any nuclear staininterstitial tissue is also necrotic and does not show any nuclear stainare thrombosed, but no thrombosis can be detected in any of the vessels lying farther away. The arteries are not thick-walled and are quite free fro $n$ any proliferation of the subintimal connective tissue.

The liver did not present any areas suggesting focal necroses to the naked eye, and on microscopical examination no such areas can be seen. The softened central portion consists of liver cells much altered in shape and shrunken in size. Some are markedly degenerate and vacuolated, others still stain well and have well-preserved nuclei. The normal arrangement of the cells, however, is destroyed, and the capillaries can no longer be made out. Here and there remains of a portal space can be made out without any thrombos

In the kirneys those portions of the cortex, which are not necrosed, still show well the normal arrangement, although the tubal epithelium shows the changes alreary describer. These changes are indistinguishable from those met with in the so-called "nephritis of pregguishable from those met with in the so-called "nepbritis of pregIt has also been shown that byaline or agglutinative thrombi are met It has also been shown that hyaline or agglutinative thrombi are met Welch ${ }^{2}$ ). On the other hand, cortical necrosis does not occur in the kidney of acute nephritis, however severe the lesion may be, nor in cases of corrosive sublimate poisoning in which the tubal epitbelium may even show calcification. It seems probable, therefore, in this case (at all events) that the necrosis, involving as it does both epithelium and interstitial tissue, is the direct sequence of the extensive thrombosis present in the vessels. Apart from the lesions present in the renal epithelium, the rapid disintegration in the liver points to there having been a grave toxæmia, and it is to this toxin, whatever its nature, that both the degeneration of the tubal epithelium and the hyalne thrombosis are due. To the latter must be attributed the final nerrosis of the cortex, which is in a state similar to that seen in anæmic infarction.

Bitliography.-1. Bradford and Lawrence : Journal of Pathology and Bactrrology, Edinburgh and London, 1898, vol. v., p. 195. 2. Griffith and Herringham: Ibid., 1905, vol. xi., p. 237. 3. Halperin : "Clinical Medicine, Chicago, 1908, vol. i., p. 320. 4. Herringham; Quarterly Journal of Medicine, Oxford, 1913, vol. vi, p. 517. 5. Jackson and Saiki: Archives of Internal Medicine, Chicago, 1912, vol. ix., p. 79 6. Jardine and Teacher: Journal of Pathology and Bacteriology, Cambridge, 1911, vol.xv., p. 137. 7. Jardine and Kennedy : TH. LANCET, London, 1913, vol. i.. p. 1291. 8. Juhel-Rénoy: Archives Générales de Médecine, Paris, 1886, vol. clvii., p. 385. 9. Klotz: American Journal of Obstetrics. New York, 1908. vol. lviii., p. 619. 10. Lloyd : THE LANCET, Londin, 1906, vol. i., p. 156. 11. Poik: New York Merlical Journal, 1883, vol. xxxvii., p. 171. 12. Torrens: The Lancer, London, 1911,
vol. i., p. 99. 13. Weber, F. P.: THE LANCET, 1909, vol. i., p. 601. 14. Welch: System of Medicine (Allbutt and Rolleston), 1909, vol. vi., p. 697 .

Upper Brook-street, W.

\section{THE EFFECT OF ALTITUDE ON BLOOD VOLUME,}

TOGETHER WITH FURTHER OBSERVATIONS ON THE BLOOD IN WARM-BLOODED AND COLD-BLOODED ANIMALS. ${ }^{3}$

BY GEORGES DREYER, M.D.,

PROFESSOR OF PATHOLOGY IN THE UNIVERSITY OF OXFORD ; AND

E. W. AINLEY WALKER, D.M.,

I.ECTURER IN PATHOLOGY IN THE UNIVERSITY OF OXFORD

\section{I. - A Contribution to the Study of the Effect of} ALTITUDE ON THE BLOOD.

IT has long been known that the effect of living at high altitudes is to cause an increase in the number of red corpuscles per cubic millimetre of blood and an increase in the hæmoglobin percentage of the blood. The effects of living under permanently increased atmospheric pressure have not been fully followed out, but data exist regarding the effect of a descent from residence at a high altitude to a lower level.

Changes also occur in the blood volume of animals placed under novel conditions as regards altitude. Those changes are of a regular character, and follow definite laws. An analysis of the entirely admirable series of observations on the influence of high altitudes on the blood recorded by A bderhalden in 1902, which contain an almost inexhaustible wealth of information, has led us to the conclusion that the change of blood volume which occurs with a particular change of barometric pressure is proportional to the area of the body surface in different individuals of a given species. The blood volume of rabbits taken up from Basel (266 metres above sea level) and kept by Abderhalden at St. Moritz (1856 metres above sea level) still conforms to our formula, $\mathrm{B}=\frac{\mathrm{W} 0.72}{\mathrm{k}}$. But $k$ is now increased. That is to. say, the blood volume is diminished by an amount exactly proportional to their body surface. For brevity we omit the long tables of calculations by means of which the value of $n$ and $k$ are determined from Abclerhalden's figures. His 20 Basel rabbits calculated by the formula $\mathrm{B}=\frac{\mathrm{W} 0.72}{\mathrm{k}}$ give a $k$ of $2 \cdot 43$, while his 19 rabbits at

St. Moritz had blood volumes which give a value for $k$ of $2 \cdot 72$. This means a diminution of blood volume of 10.7 per cent. (or nearly 11 per cent.).

At the altitude of St. Moritz the hrmoglobin percentage shows an increase, and the number of red corpuscles per cubic millimetre undergoes a parallel increase. This change is at first due entirely to a rapidly occurring concentration of the blood, as is shown by the immediate rise in the number of red corpuscles and the hæmoglobin percentage (10 per cent. or more within some 24 hours). A similar immediate concentration can be seen in the figures obtained by Douglas, Haldane, Henderson, and Schneider in man on Pike's Peak and in a number of other published observations. But in Abderhalden's figures for rabbits, which had been at St. Moritz for from four and a half to eight weeks, the percentage hæmoglobin shows an increase from $11 \cdot 74$, the figure found at Basel, to $14 \cdot 60$. This is a percentage increase in hæmoglobin percentage of $25 \cdot 1$.

If the increase in hæmoglobin percentage were entirely due at this period to concentration of the blood, the blood volume should have been reduced by 20 per cent. ; it was actually only reduced by 10.7 per cent. - that is to say, that of the percentage increase in percentage hæmoglobin 12 per cent. is due to the fall in blood volume ( $k$ rising from 243 to 2.72 ) and 13.1 per cent. is due to new formation of hæmoglobin. These together give the total increase in percentage hæmoglobin of 25.1 per cent., a decrease in blood volume of 10.7 per cent. and an increase of 11.7 per cent. in the total hæmoglobin in St. Moritz rabbits as compared with the rabbits kept at Basel as controls. Abderhalden thought that the increased production of hæmoglobin at St. Moritz was only slight and not of great importance, but our calculations from his figures show that it amounted to $11 \cdot 7$ per

1 Papers read at the meeting of the British Association for the Advancement of Science at Birmingham on Sept. 16th, 1913. 
cent. of the total hæmoglobin, thus accounting for about one half of the increased hæmoglobin percentage found at St. Moritz.

This proves the occurrence of an active new formation of blood in the course of a temporary residence of some weeks' duration at a high altitude. Thus in animals examined at the stage of Abderbalden's St. Moritz rabbits we find that about half the increase in hæmoglobin percentage is due to concentration of the blood and about half to new formation of hæmoglobin and red corpuscles. But in animals examined within a day or two of their ascent to a high altitude the whole change is due to diminution of the blood volume, Similar conclusions can be drawn from an analysis of Abderhalden's figures for oxen and swine. In their recent work on Pike's Peak (3386 metres high-14,109 feet) Douglas, Haldane, Henderson, and Schneider state that "the increased percentage of hæmoglobin on Pike's Peak was apparently due in part, during the first few days, to concentration of the blood, but afterwards entirely to a large increase in the total amount of hæmoglobin." We maintain, however, that at first the increase is entirely due to concentration of the blood, and that afterwards it is partly due to concentration of the plasma and partly to increased formation of hæmoglobin. These observers further state that "along with this increase there was (except in the first few days) a slight increase in the blood volume." But we find that taking Abderhalden's observations on animals (observations carried out with the most minute accuracy and care) the blood volume was never increased, but was diminished by more than 10 per cent.

We can now take the matter a step further by investigating the corpusoular richness of the blood in Abderhalden's rabbits. The .blood count in red corpuscles may be taken as an accurate measure of the hæmoglobin, since Abderhalden found that the hæmoglobin value per corpuscle was only very slightly increased, if at all, even after eight weeks at St. Moritz; and it certainly would not be altered after one day. Calculating, then, from six rabbits whose blood count had been determined at Basel, was again determined within one day of their arrival at St. Moritz, and then followed daily or at intervals until the last count on the day when they were washed out, we obtain the following results. After one day at St. Moritz the percentage hæmoglobin was increased from $11 \cdot 77$ to $13 \cdot 80$, an increase of $17 \cdot 3$ per cent. This corresponds to a decrease in blood volume of $14 \cdot 7$ per cent. After from $4 \frac{1}{2}$ to eight weeks at St. Moritz, when these animals were washed out, the blood volume and total hæmoglobin were determined. The blood volume was found to have decreased by 8.7 per cent. from its Basel value, and the total hæmoglobin had increased by $12 \cdot 2$ per cent. The increase in percentage hæmoglobin was from 11.77 to 14. 46-that is, an increase of 22.8 per cent. Of this increase, 9. 5 per cent. is due to the fall in the blood volume, and 13.3 per cent. is due to the new formed hæmoglobin. At the end of one day, however, at St. Moritz the percentage hæmoglobin is found to be increased from $11 \cdot 77$ to $13 \cdot 80$, an increase of 17.3 per cent., and since this can only have occurred by concentration of the plasma, the blood volume has diminished by $14 \cdot 7$ per cent. This concentration gradually undergoes a partial diminution pari passu with the new formation of hæmoglobin, so that at the end of the period of observation, when the new formed hæmoglobin amounts to $12 \cdot 2$ per cent. of the original total hæmoglobin, the blood volume is only reduced by 8.7 per cent. in these animals.

The next question is what takes place in rabbits brought back to Basel after a sojourn of from $4 \frac{1}{2}$ to 8 weeks at St. Moritz. The sequence of events may be stated as follows. When the animals were brought down again to Basel the blood diluted itself, and the blood volume reached the Basel normal in four days. The dilution did not occur so promptly after the descent as did the concentration after the ascent. In the first two days it was slight, but then became more rapid. But one cannot tell what access the rabbits may or may not have had to fluid during their return journey. At any rate, the blood volume has reached the normal for Basel after four days, and the blood constant is identical for the animals observed after four days, after five days, and after six to eight days respectively, being $2 \cdot 43$ for each set of observations (a total of 12 rabbits)-i.e., the same $k$ as the $k(2 \cdot 43)$ for rabbits which remained at Basel throughout the investigation. This finding is further supported by the fact that after the third day and onwards the daily fall in oxygen capacity runs exactly parallel to the fall in percentage hæmoglobin. It is confirmed by calculating from the long series of rabbits in which the fall in percentage hæmoglobin and in red corpuscles per cubic millimetre was followed during the first five days after the descent. Within the first four days there is no appreciable diminution at all of the total oxygen capacity. That is to say, there is no recognisable disappearance of homoglobin from the blood. After this the excess of hrmoglobin which was produced at St. Moritz begins to disappear. It is almost all gone (within 1 per cent.) in the rabbits examined between 15 and 19 days from the date of descent, their percentage hæmoglobin being 11.84 against 11.74 in the controls, and their total oxygen capacity 11.60 as compared with 11.51 in the controls.

Douglas, Haldane, Henderson, and Schneider state that "on coming down from Pike's Peak the hæmoglobin percentage diminished much more rapidly than the total hæmoglobin, so that the blood volume was still further increased at first." These results in man, from three or four individuals, are totally at variance with the results obtained from Abderhalden's long series of experiments on rabbits. 'These observers also found that it required four weeks for the excess of blood volume to disappear. In rabbits it required only four days for the diminished blood volume to increase again to the normal. They found that the percentage hæmoglobin fell to normal much before the excess of hæmoglobin disappeared. But in rabbits after the first four days the fall in percentage hæmoglobin and in total hæmoglobin run parallel during the period of gradual return to normal. It is improbable that in these respects man differs so remarkably from other mammals. But all the disagreements are capable of explanation by the fast that the CO method was used for the determinations on man. At every point of divergence the fact that a proportion of the CO breathed must go to the extravascular hæmoglobin, along with the fact that this extravascular hæmoglobin is undergoing marked changes, first in the one direction and then in the other (first a steady increase and. after the descent a steady diminution), is sufficient to explain the discrepancy in the results obtained. Indeed, it would have been possible to foretell that the results with the $\mathrm{C} 0$ method would probably exhibit just these divergences.

\section{II.-Considerations Bearing ON THE STUDY OF THE: BLOOD AND VASCULAR SYSTEM.}

The normal volume of the blood. - In mammalian animals the volume of the blood is proportional to the surface of the individual in any given species, and may be calculated from the: formula $B=\frac{W^{n}}{k}$, where $W$ is the weight of the animal in grammes, $n$ is approximately 0.72 , and $k$ is a constant to be ascertained for each particular species. This statement we have shown, in association with Dr. W. Ray, to hold for a series of mammals both wild and tame - namely, rabbit, guineapig, mouse, wild rabbit, hare, and wild rat. And in responseto criticism we have been able to confirm it absolutely for tame rabbits by an analysis of 126 independent observations collected from the literature. This analysis gave identically the same $n$ as the $n$ deduced from our own observations. In regard to birds, the other great group of warm-blooded animals, hitherto unpublished experiments carried out by us. in association with Dr. H. K. Fry on fowls, pigeons, sparrows, and dncks, show that here also the blood volume is proportional to the surface. In these observations $n$ has the value $0.70-0.72$ in the formula $B=\frac{W^{n}}{k}$, and that this. formula also accurately represents the surface area in these birds was proved by actual measurements of the surface in a. large number of cases by means of the planimeter.

That the relation thus established between the blood volume of warm-blooded animals and the area of their body surface is associated with the homoiothermic character of these animals appears to follow from the results of observations carried out in the Department of Pathology at Oxford on cold-blooded animals by Dr. Fry and embodied in his still unpublished thesis. These observations were made on lizards and frogs, and show quite clearly that in both these animals the blood volume is neither proportional to the body surface nor to the body weight. But it varies as a power greater than unity (about $1 \cdot 2$ ) of the body weight, so that the volume follows the formula $B=\frac{W 1 \cdot 21}{k}$. This indicates the fact that in these cold-blooded animals the percentage 
Blood volume actually increases as the animal grows heavier, while in the warm-blooded animals it undergoes a steady diminution. The value of $k$ as given by Fry's observations is 42.0 for frogs and $55 \cdot 5$ for lizards.

It is significant that in animals of such different shape as the lizard and the frog the value of $n$ should be the same for both. This seems to indicate an underlying relationship to which we shall return on a future occasion. ${ }^{2}$ Meanwhile, it may be stated that the value of $n$ obtained by Fry is in agreement with the value of $n$ as calculated by us from the old observations of Welcker and others on frogs. Their figures for frogs also give a $\bar{k}$ of about $42 \cdot 0$.

Further application of the surface relation.-In the course of our investigation of the blood volume of animals we had observed with interest that in those species which possessed a large blood volume the aorta was much larger than in species of a similar size which had smaller blood volumes. Accordingly we carried out a series of observations, in association with Dr. Ray, upon the sectional area of the aorta just abore the semilunar valves. Here, again, we were able to show quite definitely that in both mammals and birds the sectional area of the aorta is proportional to the body surface and conforms to the formula $A=\frac{W^{n}}{k}$, where the value of $n$ is $0.70-0.72$. The sectional area of the trachea was also found to be proportional to the body surface. An interesting point now emerges from a consideration of our figures for guinea-pigs and rabbits. The rabbit has relatively a good deal more blood than the guinea-pig, and accordingly its aorta is relatively larger. On the other hand, it has much less hæmoglobin than the guinea-pig, but its trachea is very much larger, thus doubtless rendering easier the intake of wygen.

A further point of interest may be mentioned herenamely, that in examining animals of different species we bave found the ratio of the weight of the heart muscle to the total oxygen capacity of the circulating blood to be approximately constant from species to species in a number of cases.

Influence of sex.-As regards sex, we find that in the mammals which we have examined the blood volume is some. what smaller (about 3 per cent.) in the female animal than in the male of the same weight. This relationship is, however, altered during pregnancy and in the puerperal condition, when the blood volume of the female is considerably increased. The sectional area of the aorta is also smaller in the female than in the male of corresponding weight, while so far as our observations go, that of the trachea is somewhat larger in the female than in the male. Thus the male which has the larger blood volume has a larger aorta, while the female, which has a somewhat lower percentage of hæmoglobin in its blood than the male, is provided with a relatively wider trachea for the admission of oxygen. This difference between the sexes within the same species is of the same character as the differences in the blood volume, aortic cross section, hæmoglobin percentage and tracheal area existing between different species, already pointed out above, in comparing the rabbit with the guinea-pig. In drawing attention to these facts we intentionally omit for the present any reference to certain other factors which we know to be of importance-namely, the velocity of the blood flow, the frequency of the heart beat, the rate of the respiration, and the amount of the respiratory exchange.

Influense of age and species.-As regards age, by which we here imply the progressive increase of the animal in size and weight up to full growth, it may be stated that in any given species younger and lighter animals possess a lower percentage of hæmoglobin both in their circulating blood and in their muscles than the older and heavier individuals. And since, as Ranke showed, the muscles increase more than in proportion to the increase in body weight, it follows that the muscle hæmoglobin increases relatively much more rapidly than the weight of the animal. This fact is. as we have previously pninted out, an important source of error in the application of the CO method for the determination of Blood volume.

In different species it is strikingly evident that the mode

2 This relationship in the frog is a relationship to the mass of the asteomuscular system, which also follows the formula $M=\frac{W 121}{k}$. of life and muscular activity of the species is a factor of importance in determining the amount and the distribution of the hæmoglobin in the body. Animals which have a high hæmoglobin percentage in their blood have in general a high hæmoglobin percentage in their muscles, and in consequence dark flesh, while those which have a lower hæmoglobin percentage in the blood have also a lower percentage in the muscles and have pale or white flesh. This is seen on comparing wild rabbits with tame rabbits, hares with wild rabbits, ducks with fowls, and adult animals with younger animals of the same species. Moreover, on comparing the hare with the wild rabbit it is seen that the former animal, which exhibits both great endurance and remarkable speed, has a higher hæmoglobin percentagle, darker muscles, a heavier heart, and a larger aorta than the latter, whose natural mode of life calls for less exhibition of long main. tained muscular effort and staying power. The hare has more than double the blood volume, 30 per cent. more hæmoglobin in its blood, and about three times as much heart muscle as a wild rabbit of the same size. Similar facts apply to particular muscles and groups of muscles in different animals. The wing muscles of birds which fly are always dark in different degrees, while those of fowls are pale. But in all animals the heart, diaphragm, and intercostal muscles are always dark.

The regulation of the volume of the blood. - Under normal conditions the volume of the blood of mammals is very delicately adjusted. The restoration of volume, which, as is well known, quickly occurs after hæmorrhage or transfusion (whether of defibrinated blood or of isotonic saline solutions), begins immediately. It is already recognisable by a definite and measurable change in the hæmoglobin percentage when only a very small percentage of fluid has been removed or introduced. This fact adversely affects the value of many of the experiments which have been carried out on bleeding and transfusion, since it has evidently escaped due recognition. The application of an elastic bandage to a limb has practically the effect of a transfusion of blood by considerably increasing the volume of the blood circulating in the now diminished vascular area. Accordingly it is found that a rapid concentration of the blood indicated by an increase in the hæmoglobin percentage occurs and is already recognisable within a few minutes of the application of the bandage. On remoring the bandage the blood quickly restores itself to its former volume by a process of dilution. The effect of cold or warmth applied to the surface is largely comparable to the effect of applying an elastic bandage or removing one from from a limb. By its effect upon the superficial vessels it leads to a concentration or dilution of the blood as the case may be.

In further experiments the effect of certain chemical substances on the volume and concentration of the blood has been investigated. In many experiments on the blood and respiration it has hitherto been tacitly assumed that the blood volume undergoes no significant alteration during the period of observation. We find, however, that this is not the case. The presence of an increased amount of carbon dioxide in the respired air 'produced by breathing into a confined space quickly leads to a dilution of the plasma and an increase of blood volume which may amount to 10 per cent. or even more. This is a new factor which will come into account in interpreting many of the experiments carried out by respiratory methods. The inhalation of oxygen, on the other hand, leaves the blood volume unaltered. The administration of amyl nitrite which causes vascular dilatation also leads to an immediate dilution of the plasma. This observation renders it unlikely that an abiding fall in the blood pressure can be brought about under normal con. ditions by the production of active vaso-dilatation. The introduction into animals of chloral hydrate in quantities sufficient to cause anæsthesia produces rapid concentration of the blood with a corresponding diminution of blood volume. This has been demonstrated not cnly by estimating the increase which occurs in the hæmoglobin percentage, but also by direct determination of the blood volume by means of washing out experiments. The degree of concentration varies with the dosage - a fact of importance in relation to the pharmacological action of this drug, and one which renders it an unsuitable anæsthetic to employ in work upon the blood and circulation. On the other hand, ether anæsthesia leaves the volume of the blood unal' ered. 